\title{
Effect of nurse-led telephone follow-up on postoperative symptoms and analgesics consumption after benign hysterectomy: a randomized, single-blinded, four-arm, controlled multicenter trial.
}

Gulnara Kassymova ( $\sim$ gulka007@ad.liu.se)

Linköping University: Linkopings universitet https://orcid.org/0000-0002-5386-932X

Gunilla Sydsjö

Linköping University

Ninnie Borendal Wodlin

Linköping University

Lena Nilsson

Linköping University

Preben Kjølhede

Linköping University

\section{Research Article}

Keywords: Coaching, ERAS, Hysterectomy, Postoperative symptoms, Telephone follow-up

Posted Date: February 1st, 2022

DOI: https://doi.org/10.21203/rs.3.rs-1269821/v1

License: (c) (i) This work is licensed under a Creative Commons Attribution 4.0 International License. Read Full License 


\section{Abstract}

Purpose. The study aimed to determine if planned telephone follow-up especially when adding structured, oriented coaching, reduces the intensity of postoperative symptoms and decreases analgesics consumption after benign hysterectomy.

Methods. A randomized, single-blinded, four-armed, controlled multicenter trial of 525 women scheduled for hysterectomy in was conducted in five hospitals in the southeast health region of Sweden. The women were allocated 1:1:1:1 into four follow-up models: A) no telephone follow-up (control group); B) one planned, structured, telephone follow-up the day after discharge; $\mathrm{C}$ ) as $\mathrm{B}$ but with additional telephone follow-up once weekly for six weeks; and D) as C but with oriented coaching telephone followup on all occasions. Postoperative symptoms were assessed by using the Swedish Postoperative Symptoms Questionnaire. Analgesic consumption was registered. Unplanned telephone contacts and visits were registered during the six weeks of follow-up.

Results: In total, 487 women completed the study. Neither pain intensity, nor symptom sum score or analgesic consumption differed between the intervention groups. Altogether, 224 (46.0\%) women had unplanned telephone contacts and 203 (41.7\%) had unplanned visits. Independent of intervention, the women with unplanned telephone contacts had higher pain intensity and symptom sum scores, particularly if an unplanned telephone contact was followed by a visit, or an unplanned visit was preceded by an unplanned telephone contact.

Conclusion: Telephone follow-up did not seem to affect recovery regarding symptoms or analgesic consumption after benign hysterectomy in an ERAS setting. Unplanned telephone contacts and visits were associated with more postoperative symptoms, especially pain.

Trial registration. The study is registered in ClinicalTrial.gov: NCT01526668 retrospectively from January 27; 2012. Date of enrolment of first patient: October 11; 2011

\section{Introduction}

Patients may still experience discomfort in the recovery period after hysterectomy in spite of the use of enhanced recovery after surgery (ERAS) multimodal programs aimed at minimizing the pathophysiological changes associated with surgery [1]. A variety of symptoms e.g. pain, postoperative nausea and vomiting, fatigue, gastrointestinal symptoms, and itching are commonly reported after hysterectomy [2]. Thus, it seems necessary to add interventions that may influence the experience of postoperative symptoms.

The early and intermediate phases of recovery take place while the patient is still in hospital $[3,4]$. In the late recovery phase, i.e. after discharge from hospital, the patient self-manages the postoperative symptoms using the information/education obtained through the ERAS program and the prescribed 
medication. If the provided treatment is inadequate or new discomforts occur, the patient may initiate a contact with a health care provider.

Routine follow-up contacts after hysterectomy on benign indication are not common praxis in Sweden. However, qualitative studies have indicated that women strongly believe that the recovery after surgery would benefit from follow-up contact by nurses [5-8]. Gynecological clinics may therefore be attempted to implement nurse-led telephone follow-up (TFU) after discharge. The content of the TFU has not been standardized or evaluated, and no evidence for the benefit of such contacts has been reported. We performed a randomized controlled four-armed multicenter trial (the Post-hysterectomy recovery (POSTHYSTREC) trial), comparing three nurse-led TFU programs and a control with no TFU after benign hysterectomy, in order to investigate whether TFU in an ERAS setting accelerates recovery. No effect on recovery of health-related quality of life of the four modes of follow-up was found, but the number of unplanned telephone contacts (UTC) was significantly lower after a structured oriented coaching TFU [9]. The present study constitutes secondary outcomes from the POSTHYSTREC trial.

The primary aim of this study was to determine if different nurse-led TFU strategies, including structured oriented coaching, affect postoperative symptoms. The secondary aims were to determine TFUs impact on consumption of analgesics, and to analyze the impact on postoperative symptoms and consumption of analgesics in women who had UTC and unplanned visits (UV) during the first six weeks postoperatively.

\section{Material And Methods}

The POSTHYSTREC trial, a randomized single-blinded, controlled multicenter intervention trial of women undergoing hysterectomy on benign indication, was undertaken at the departments of obstetrics and gynecology in five hospitals in the southeast region of Sweden between October 2011 and May 2017.

The study has previously been described in detail including power analysis [9]. Briefly, women scheduled for abdominal (total or subtotal), or vaginal hysterectomy, aged 18 to 60 years, were included in the study after receiving written and verbal information and providing signed informed consent. Speaking Swedish fluently and having access to a phone or the internet was a requirement. Women scheduled for hysterectomy due to genital prolapse, cancer heredity, or suspected /confirmed invasive gynecological malignancies were excluded. Moreover, exclusion criteria were previously or planned bilateral oophorectomy, mental and physical disability, severe mental illness, current drug or alcohol abuse.

The pre- and postoperative care followed the ERAS program $[10,11]$. The mode of hysterectomy was decided by the gynecologist after consultation with the patient before enrolment in the study.

A computer generated the randomization code [12] with an allocation ratio of 1:1:1:1. The allocated intervention was written on a paper enclosed in consecutively numbered sealed opaque envelopes. A block randomization method was used, with allocation and stratification for center and abdominal or vaginal hysterectomy. The participants were randomized before surgery in order of the numbered 
envelopes. All participants were informed that there would be follow-up contact with the research nurse (RN) postoperatively but the frequency of the follow-up contact was concealed, and was first revealed to the woman at the time of opening the randomization envelope at discharge. Thus, the participants were blinded to the content and the frequency of the follow-up contact.

Women were randomized to one of four follow-up programs.

- Group A - no planned follow-up contact after discharge. The patient was requested to initiate contact if necessary.

- Group B - one planned TFU with the RN the day after discharge. Thereafter the patient was requested to initiate contact if necessary.

- Group C - planned TFU with the RN the day after discharge and then once weekly for six weeks.

- Group D - planned, structured, oriented coaching TFU with the RN the day after discharge, and then once weekly for six weeks.

The content of the TFU and coaching, including education of the RNs, is described in detail [9]. The structured, oriented coaching was an experimental intervention based on elements from Cognitive Behavior Therapy (CBT) and clinical experience.

All women were seen by the RN for collection of the questionnaires and diary at the end of the trial six weeks postoperatively.

\section{Swedish Postoperative Symptoms Questionnaire (SPSQ)}

The SPSQ is a validated questionnaire that measures common postoperative symptoms such as nausea, retching, headache, abdominal pain, tiredness, drowsiness, blurred vision, and itching [1-2]. The intensity of each symptom was rated as 'none' (1), 'yes, a little' (2), 'yes, somewhat' (3) and 'yes, a 'lot' (4). The sum score of these eight symptoms, which constituted a measurement of the overall discomfort, ranged between 8 and 32: the higher sum score, the greater discomfort. Woman reported the maximum experienced intensity of the pain, i.e. when the pain was at its worst, and how the pain was felt on average on the particular day. The maximum and average pain intensities were rated on a seven-point scale as: "none" (0), "very mild" (1), "mild" (2), "moderate" (3), "bad" (4), "severe" (5), and "very severe" (6). The SPSQ questionnaire was completed once daily at the same time during the first postoperative week, starting the evening after surgery and thereafter once weekly until six weeks postoperatively.

Women received standardized postoperative analgesics consisting of oral paracetamol $665 \mathrm{mg}$ two tablets three times daily, diclofenac $50 \mathrm{mg}$ three times daily and oxycodone 10-20 mg twice daily. At discharge the patient received prescriptions of oral non-opioids (paracetamol and diclofenac) and if necessary weak opioid-containing analgesics (codeine or tramadol). Consumption of analgesic was registered in the patient's record during hospitalization. After discharge, the patient reported the daily consumption in a diary. The daily dose of opioids was converted into an equivalent intravenous dose of 
morphine and the daily dose of non-opioids was converted to the World Health Organization's defined daily dose [13].

Demographic and clinical data were collected prospectively from the time of inclusion until the scheduled end-of-study visit six weeks after the hysterectomy. uTCs and uVs with health care providers after discharge up to the six-week follow-up visit were registered.

\section{Outcome measures}

Primary outcome measures were maximum and average pain intensities and symptoms sum score. Secondary outcomes were consumption of opioid and non-opioid analgesics, uTCs, and uVs.

\section{Statistical analyses}

Data were analyzed using the software TIBCO Statistica ${ }^{\circledR}$ 13.5.0 (TIBCO Software Inc., Palo Alto, CA 94304 USA). Measures of central tendency and dispersion are reported as mean and standard deviation. Categorical data are presented as number and percent. Comparison of groups was done by use of oneway analysis of variance (ANOVA) for normal distributed continuous data and Kruskal-Wallis ANOVA for non-normally distributed continuous data. Nominal data were analyzed by means of Pearson's chisquared tests.

Data measured on repeated occasions were analyzed by means of repeated measures ANOVA. Post-hoc tests for between-group comparisons were conducted using Tukey's honestly significant difference tests. Non-normally distributed variables were logarithmically transformed and used as such in the analysis. The repeated measures ANOVA models were adjusted for mental disorder, mode of surgery, consumption of opioids day 2-7, non-opioids day 2-15, day of discharge (categorized), and intervention. The level of significance was set at $p<0.05$ for two-tailed tests.

Missing data of an item in the SPSQ on an occasion of measurement was replaced by the mean value of the item of the intervention group on the specific occasion. The number of missing cells in the SPSQ made up 3.2\% concerning maximum pain intensity, 3.5\% for average pain intensity, and $4.1 \%$ for the items of the symptom sum score.

\section{Results}

The flow chart of the study population is presented in Figure 1. Demographic and clinical data are reported in Table 1. The groups were balanced in baseline data except for the preoperative occurrence of mental disorder in $19.2 \%, 6.6 \%, 16.0 \%$ and $11.7 \%$ of Groups A, B, C and D, respectively. The daily consumption of analgesics postoperatively and background data concerning outcomes of the SPSQ on day 0 (day of surgery) and day 1 are presented in Table 2. Opioid consumption is shown for only eight days and the non-opioid consumption for 16 days due to very low consumption of the respective analgesics after these days. 
Table 1

Demographic and clinical descriptive data of 487 women undergoing benign hysterectomy subdivided after intervention group.

\begin{tabular}{|c|c|c|c|c|c|}
\hline & & $\begin{array}{l}\text { Group A } \\
(n=120)\end{array}$ & $\begin{array}{l}\text { Group B } \\
(n=122)\end{array}$ & $\begin{array}{l}\text { Group C } \\
(n=125)\end{array}$ & $\begin{array}{l}\text { Group D } \\
(n=120)\end{array}$ \\
\hline \multicolumn{2}{|l|}{ Age (years) } & $45.5(5.3)$ & $47.2(5.6)$ & $46.2(5.3)$ & $47.0(5.8)$ \\
\hline \multicolumn{2}{|l|}{$<40$ years } & $18(15.0)$ & $14(11.5)$ & $21(16.8)$ & $14(11.7)$ \\
\hline \multicolumn{2}{|l|}{ Between 40 and 50 years } & $83(59.2)$ & $76(62.3)$ & $79(63.2)$ & $76(63.3)$ \\
\hline \multicolumn{2}{|l|}{$>50$ years } & $19(15.8)$ & $32(26.2)$ & $25(20.0)$ & $30(25.0)$ \\
\hline \multicolumn{2}{|l|}{ BMI $\left(k g / m^{2}\right)$} & $26.8(4.8)$ & $27.0(4.8)$ & $26.7(4.6)$ & $26.5(4.6)$ \\
\hline \multicolumn{2}{|l|}{$\leq 25.0 \mathrm{~kg} / \mathrm{m}^{2}$} & $53(44.1)$ & $49(40.2)$ & $60(48.0)$ & $56(46.7)$ \\
\hline \multicolumn{2}{|l|}{$>25.0$ and $-29.9 \mathrm{~kg} / \mathrm{m}^{2}$} & $38(31.7)$ & $43(35.2)$ & $35(28.0)$ & $40(33.3)$ \\
\hline \multicolumn{2}{|l|}{$\geq 30.0 \mathrm{~kg} / \mathrm{m}^{2}$} & $29(24.2)$ & $30(24.6)$ & $30(24.0)$ & $24(20.0)$ \\
\hline \multicolumn{2}{|l|}{ Nulliparous } & $10(8.4)$ & $19(15.8)$ & $15(12.0)$ & $20(16.7)$ \\
\hline \multicolumn{2}{|l|}{ Smoking } & $18(15.5)$ & $9(7.6)$ & $18(14.4)$ & $11(9.6)$ \\
\hline \multirow[t]{2}{*}{ Gainfully employment } & Yes & $\begin{array}{l}107 \\
(89.2)\end{array}$ & $\begin{array}{l}117 \\
(95.9)\end{array}$ & $\begin{array}{l}111 \\
(88.8)\end{array}$ & $\begin{array}{l}113 \\
(94.2)\end{array}$ \\
\hline & No & $13(10.8)$ & $5(4.1)$ & $14(11.2)$ & $7(5.8)$ \\
\hline \multirow[t]{2}{*}{ Co-morbidity } & Mental disorders $†$ & $23(19.2)$ & $8(6.6)$ & $20(16.0)$ & $14(11.7)$ \\
\hline & Chronic pain disorder & $28(23.3)$ & $30(24.6)$ & $29(23.2)$ & $31(25.8)$ \\
\hline \multicolumn{6}{|c|}{ Taking medicine regularly preoperatively } \\
\hline \multirow[t]{2}{*}{ Analgesics } & $\begin{array}{l}\text { Non opioid } \\
\text { analgesics }\end{array}$ & $14(11.7)$ & $20(16.4)$ & $22(17.6)$ & $11(9.2)$ \\
\hline & Opioid analgesics & $4(3.3)$ & $3(2.5)$ & $6(4.8)$ & $6(5.0)$ \\
\hline \multicolumn{2}{|l|}{ Hypnotics } & $8(6.7)$ & $2(1.6)$ & $7(5.6)$ & $7(5.8)$ \\
\hline
\end{tabular}

Figures denote mean and (standard deviation) or number of women and (percent).

ASA, American Society of Anesthesiologists; GA, general anesthesia; IT, intrathecal; ITA, intrathecal anesthesia.

† Mental disorders comprise minor mental disorders such as anxiety, panic, depressive and mood disorders, and phobias.

* Day of discharge: Day of surgery = Day 0. 


\begin{tabular}{|c|c|c|c|c|c|}
\hline & & $\begin{array}{l}\text { Group A } \\
(n=120)\end{array}$ & $\begin{array}{l}\text { Group B } \\
(n=122)\end{array}$ & $\begin{array}{l}\text { Group C } \\
(n=125)\end{array}$ & $\begin{array}{l}\text { Group D } \\
(n=120)\end{array}$ \\
\hline $\begin{array}{l}\text { Hysterectomy } \\
\text { indication }\end{array}$ & Myoma uteri & $58(48.3)$ & $65(53.3)$ & $47(37.6)$ & $53(44.2)$ \\
\hline Bleeding disorder & & $32(26.7)$ & $23(18.8)$ & $35(28.0)$ & $35(29.2)$ \\
\hline Myoma and bleeding & & $10(8.3)$ & $14(11.5)$ & $21(16.8)$ & $13(10.8)$ \\
\hline Cervical dysplasia & & $14(11.7)$ & $12(9.8)$ & $14(11.2)$ & $9(7.5)$ \\
\hline Pain & & $5(4.2)$ & $8(6.6)$ & $8(6.4)$ & $9(7.5)$ \\
\hline Others & & $1(0.8)$ & $0(0.0)$ & $0(0.0)$ & $1(0.8)$ \\
\hline \multirow[t]{3}{*}{ ASA classification } & Class 1 & $84(70.0)$ & 78 (63.9) & $79(63.2)$ & 79 (65.8) \\
\hline & Class 2 & $35(29.2)$ & $40(32.8)$ & $39(31.2)$ & $39(32.5)$ \\
\hline & Class 3 & $1(0.8)$ & $4(3.3)$ & $7(5.6)$ & $2(1.7)$ \\
\hline \multirow[t]{2}{*}{ Mode of hysterectomy } & Abdominal & $97(80.8)$ & $98(80.3)$ & $98(78.4)$ & $90(75.0)$ \\
\hline & Vaginal & $23(19.2)$ & $24(19.7)$ & $27(21.6)$ & $30(25.0)$ \\
\hline \multirow[t]{3}{*}{ Mode of anesthesia } & GA & $55(45.8)$ & $37(30.3)$ & $50(40.0)$ & $41(34.2)$ \\
\hline & ITA + IT morphine & $34(28.4)$ & $52(42.6)$ & $45(36.0)$ & $49(40.8)$ \\
\hline & GA + IT morphine & $31(25.8)$ & $33(27.1)$ & $30(24.0)$ & $30(25.0)$ \\
\hline Hospital stay (days) & & $1.8(1.1)$ & $1.8(1.3)$ & $1.6(1.0)$ & $1.6(1.2)$ \\
\hline \multirow[t]{4}{*}{ Day of discharge* } & Day 1 & $47(39.2)$ & $53(43.4)$ & $50(40.0)$ & $64(53.3)$ \\
\hline & Day 2 & $60(50.0)$ & $55(45.1)$ & $62(49.6)$ & $48(40.0)$ \\
\hline & Day 3 & $8(6.7)$ & $10(8.2)$ & $7(5.6)$ & $7(5.8)$ \\
\hline & Day 4 or later & $5(4.2)$ & $4(3.3)$ & $6(4.8)$ & $1(0.8)$ \\
\hline \multicolumn{6}{|c|}{ Figures denote mean and (standard deviation) or number of women and (percent). } \\
\hline \multicolumn{6}{|c|}{$\begin{array}{l}\text { ASA, American Society of Anesthesiologists; GA, general anesthesia; IT, intrathecal; ITA, intrathecal } \\
\text { anesthesia. }\end{array}$} \\
\hline \multicolumn{6}{|c|}{$\begin{array}{l}\text { † Mental disorders comprise minor mental disorders such as anxiety, panic, depressive and mood } \\
\text { disorders, and phobias. }\end{array}$} \\
\hline \multicolumn{6}{|c|}{ * Day of discharge: Day of surgery = Day 0.} \\
\hline
\end{tabular}


Table 2

A) daily consumption of opioids (equivalent iv. morphine dose (mg)) and non-opioids (in DDD) day-by day in 487 women undergoing benign hysterectomy in relation to intervention group, and B) background data concerning outcomes of the SPSQ on day 0 (day of surgery) and day 1.

\begin{tabular}{|c|c|c|c|c|c|c|}
\hline & Day $^{\dagger}$ & $\begin{array}{l}\text { Group A } \\
(n=120)\end{array}$ & $\begin{array}{l}\text { Group B } \\
(n=122)\end{array}$ & $\begin{array}{l}\text { Group C } \\
(n=125)\end{array}$ & $\begin{array}{l}\text { Group D } \\
(n=120)\end{array}$ & p-value* \\
\hline \multicolumn{7}{|l|}{ A } \\
\hline \multirow[t]{8}{*}{$\begin{array}{l}\text { Equivalent iv. morphine } \\
\text { (mg) }\end{array}$} & 0 & $\begin{array}{l}10.1 \\
(12.2)\end{array}$ & $\begin{array}{l}7.7 \\
(11.3)\end{array}$ & $8.6(10.0)$ & $8.9(13.0)$ & 0.41 \\
\hline & 1 & $4.7(7.4)$ & $4.5(7.2)$ & $5.8(8.6)$ & $4.1(6.0)$ & 0.13 \\
\hline & 2 & $2.9(5.8)$ & $3.3(7.4)$ & $3.8(6.3)$ & $2.8(5.6)$ & 0.17 \\
\hline & 3 & $2.1(4.7)$ & $1.8(4.6)$ & $2.2(4.6)$ & $2.2(4.8)$ & 0.42 \\
\hline & 4 & $1.4(3.8)$ & $1.8(6.5)$ & $1.6(4.3)$ & $1.5(3.7)$ & 0.61 \\
\hline & 5 & $0.8(2.7)$ & $1.3(5.3)$ & $1.0(3.0)$ & $0.9(3.6)$ & 0.44 \\
\hline & 6 & $0.7(2.6)$ & $0.9(4.9)$ & $0.7(2.6)$ & $0.2(1.1)$ & 0.21 \\
\hline & 7 & $0.4(1.7)$ & $0.9(4.6)$ & $0.7(2.6)$ & $0.4(2.5)$ & 0.32 \\
\hline \multirow[t]{11}{*}{ Non-opioids (DDD) } & 0 & $1.7(0.9)$ & $1.9(0.8)$ & $1.7(1.1)$ & $1.8(0.9)$ & 0.21 \\
\hline & 1 & $2.3(0.9)$ & $2.1(1.0)$ & $2.1(1.0)$ & $2.2(1.0)$ & 0.32 \\
\hline & 2 & $2.1(1.0)$ & $2.2(1.1)$ & $2.1(1.1)$ & $2.1(1.2)$ & 0.77 \\
\hline & 3 & $1.9(1.1)$ & $1.9(1.1)$ & $2.0(1.1)$ & $2.0(1.1)$ & 0.93 \\
\hline & 4 & $1.9(1.1)$ & $1.7(1.1)$ & $1.8(1.1)$ & $1.9(1.1)$ & 0.68 \\
\hline & 5 & $1.7(1.1)$ & $1.6(1.2)$ & $1.6(1.1)$ & $1.7(1.1)$ & 0.56 \\
\hline & 6 & $1.5(1.1)$ & $1.4(1.1)$ & $1.5(1.1)$ & $1.4(1.2)$ & 0.88 \\
\hline & 7 & $1.4(1.1)$ & $1.4(1.1)$ & $1.4(1.1)$ & $1.2(1.1)$ & 0.35 \\
\hline & 8 & $1.2(1.1)$ & $1.2(1.0)$ & $1.2(1.1)$ & $1.1(1.1)$ & 0.98 \\
\hline & 9 & $1.1(1.0)$ & $1.1(1.0)$ & $1.0(1.0)$ & $1.0(1.1)$ & 0.65 \\
\hline & 10 & $0.9(0.9)$ & $1.0(1.0)$ & $0.9(0.9)$ & $0.9(1.0)$ & 0.64 \\
\hline
\end{tabular}

Figures denote mean and (standard deviation)

$\dagger$ Day $0=$ day of surgery.

* Kruskal Wallis ANOVA.

DDD = defined daily dose 


\begin{tabular}{|c|c|c|c|c|c|c|}
\hline & Day $^{\dagger}$ & $\begin{array}{l}\text { Group A } \\
(n=120)\end{array}$ & $\begin{array}{l}\text { Group B } \\
(n=122)\end{array}$ & $\begin{array}{l}\text { Group C } \\
(n=125)\end{array}$ & $\begin{array}{l}\text { Group D } \\
(n=120)\end{array}$ & p-value* \\
\hline & 11 & $0.8(0.9)$ & $0.9(0.9)$ & $0.8(0.9)$ & $0.8(1.0)$ & 0.66 \\
\hline & 12 & $0.7(0.8)$ & $0.8(0.9)$ & $0.8(0.9)$ & $0.7(0.9)$ & 0.78 \\
\hline & 13 & $0.5(0.8)$ & $0.7(0.9)$ & $0.6(0.9)$ & $0.6(0.8)$ & 0.64 \\
\hline & 14 & $0.5(0.7)$ & $0.6(0.8)$ & $0.6(0.8)$ & $0.5(0.8)$ & 0.80 \\
\hline & 15 & $0.4(0.7)$ & $0.4(0.7)$ & $0.5(0.8)$ & $0.4(0.8)$ & 0.90 \\
\hline \multicolumn{7}{|l|}{ B } \\
\hline \multirow[t]{2}{*}{ Maximum pain intensity } & 0 & $3.8(1.6)$ & $3.0(1.7)$ & $3.4(1.7)$ & $3.2(1.6)$ & $<0.001$ \\
\hline & 1 & $3.4(1.5)$ & $3.4(1.5)$ & $3.3(1.5)$ & $3.3(1.2)$ & 0.90 \\
\hline \multirow[t]{2}{*}{ On average pain intensity } & 0 & $3.0(1.4)$ & $2.6(1.7)$ & $2.8(1.5)$ & $2.6(1.4)$ & 0.11 \\
\hline & 1 & $2.9(1.3)$ & $2.8(1.3)$ & $2.7(1.3)$ & $2.8(1.2)$ & 0.82 \\
\hline \multirow[t]{2}{*}{ Symptom sum score } & 0 & $16.5(4.7)$ & $\begin{array}{l}15.5 \\
(4.5)\end{array}$ & $15.9(4.1)$ & $16.2(3.6)$ & 0.26 \\
\hline & 1 & $14.2(4.2)$ & $\begin{array}{l}13.8 \\
(4.0)\end{array}$ & $14.1(4.0)$ & $13.7(3.6)$ & 0.76 \\
\hline \multicolumn{7}{|c|}{ Figures denote mean and (standard deviation) } \\
\hline \multicolumn{7}{|l|}{ † Day 0 = day of surgery. } \\
\hline \multicolumn{7}{|l|}{ * Kruskal Wallis ANOVA. } \\
\hline $\mathrm{DDD}=$ defined daily dose & & & & & & \\
\hline
\end{tabular}

No significant difference was found between the intervention groups in any of the recovery outcomes (maximum pain intensity, average pain intensity, symptom sum score, and consumption of opioids and non-opioids), as shown in Figures 2-4. The results remained when adjusted for mental disorder, mode of hysterectomy, consumption of opioids and non-opioids, and day of discharge. The level of the outcome measures decreased significantly over time, and no interaction effects were observed.

By adding the other factors depicted in Table 1 separately into the adjusted repeated measures ANOVA models, the outcome of the intervention remained insignificant, indicating that no subgroup among the factors would benefit from the intervention (data not shown).

Two hundred forty-six (46.0\%) women had a uTC between discharge and the planned six-week follow-up visit. Of these 80 (35.7\% (80/224)) had no following visit whereas 144 women $(64.3 \%(144 / 224))$ had a following visit. Totally, 203 women (41.7\%) had a uV. The visit was preceded by a uTC for 144 women (70.9\% (144/203)). 
The results of the repeated measures ANOVA of the recovery outcome measures in relation to the grouping of uTCs or UVs and the influence of the interventions are presented in Table 3. Significant associations were found between the groups concerning maximum and average pain intensity and symptom sum scores for both uTCs and uVs, whereas consumption of opioids and non-opioids did not differ between groups. The interventions per se did not independently affect any of the recovery outcome measures in the uTC or the uV groups.

Table 3

Associations between the recovery outcome measures and A): the three groups, a) those without unplanned telephone contact and $\mathrm{b}$ ) those with unplanned telephone contact with a following unplanned visit, and c) those without a following unplanned visit. B): the three groups, a) those without an unplanned visit and $\mathrm{b}$ ) those with an unplanned visit preceded by an unplanned telephone contact, and $\mathrm{c}$ ) those with an unplanned visit without a preceded unplanned telephone contact.

\begin{tabular}{|c|c|c|c|c|}
\hline \multicolumn{5}{|c|}{ Repeated measures analysis of variance } \\
\hline & $\begin{array}{l}\text { Between the three } \\
\text { groups }\end{array}$ & \multicolumn{2}{|l|}{ Within groups } & \multirow[t]{2}{*}{$\begin{array}{l}\text { Effect of } \\
\text { interventior }\end{array}$} \\
\hline & Main effect & $\begin{array}{l}\text { Effect over } \\
\text { time }\end{array}$ & $\begin{array}{l}\text { Interaction } \\
\text { effect }\end{array}$ & \\
\hline Outcome measure & $\mathrm{p}$-value & p-value & p-value & $\mathrm{p}$-value \\
\hline $\begin{array}{l}\text { Maximum pain } \\
\text { intensity\# }\end{array}$ & $<0.0001$ & $<0.0001$ & 0.51 & 0.97 \\
\hline $\begin{array}{l}\text { On average pain } \\
\text { intensity\# }\end{array}$ & $<0.0001$ & $<0.0001$ & 0.85 & 0.80 \\
\hline Symptom sum score\# & $<0.0001$ & $<0.0001$ & 0.25 & 0.27 \\
\hline Opioid consumption $^{\dagger}$ & 0.30 & 0.21 & 0.79 & 0.56 \\
\hline $\begin{array}{l}\text { Non-opioid } \\
\text { consumption }\end{array}$ & 0.81 & $<0.0001$ & $<0.01$ & 0.96 \\
\hline
\end{tabular}




\begin{tabular}{|c|c|c|c|c|}
\hline \multirow[t]{3}{*}{ B. Unplanned visit } & \multicolumn{4}{|c|}{ Repeated measures analysis of variance } \\
\hline & \multirow{2}{*}{$\begin{array}{l}\text { Between the three } \\
\text { groups } \\
\text { Main effect }\end{array}$} & \multicolumn{2}{|c|}{ Within groups } & \multirow[t]{2}{*}{$\begin{array}{l}\text { Effect of } \\
\text { intervention }\end{array}$} \\
\hline & & $\begin{array}{l}\text { Effect over } \\
\text { time }\end{array}$ & $\begin{array}{l}\text { Interaction } \\
\text { effect }\end{array}$ & \\
\hline Outcome measure & $p$-value & p-value & p-value & $\mathrm{p}$-value \\
\hline $\begin{array}{l}\text { Maximum pain } \\
\text { intensity\# }\end{array}$ & $<0.0001$ & $<0.001$ & 0.36 & 0.90 \\
\hline $\begin{array}{l}\text { On average pain } \\
\text { intensity\# }\end{array}$ & $<0.0001$ & $<0.001$ & 0.72 & 0.81 \\
\hline Symptom sum score\# & $<0.0001$ & $<0.0001$ & 0.40 & 0.75 \\
\hline Opioid consumption ${ }^{+}$ & 0.18 & 0.19 & 0.76 & 0.58 \\
\hline $\begin{array}{l}\text { Non-opioid } \\
\text { consumption }\end{array}$ & 0.91 & $<0.0001$ & 0.08 & 0.94 \\
\hline \multicolumn{5}{|c|}{$\begin{array}{l}\text { \# Measured daily from day } 2 \text { after surgery to day } 7 \text { and then once weekly until six weeks } \\
\text { postoperatively. Adjusted for mental disorder, mode of surgery, consumption of opioids day 2-7, non- } \\
\text { opioids day 2-15, day of discharge (categorical), and intervention. }\end{array}$} \\
\hline \multicolumn{5}{|c|}{$\begin{array}{l}\text { † Opioid consumption day } 2 \text { to day } 7 \text {, adjusted for mental disorder, consumption of non-opioids day } \\
2-7 \text {, day of discharge (categorical), and intervention. }\end{array}$} \\
\hline \multicolumn{5}{|c|}{$\begin{array}{l}\text { ₹ Non-opioid consumption day } 2 \text { to day } 15 \text {, adjusted for mental disorder, consumption of opioids day } \\
2-7 \text {, day of discharge (categorical), and intervention. }\end{array}$} \\
\hline
\end{tabular}

The results of the post-hoc analyses are graphically shown in Figure 5. In summary, the maximum and average pain intensity, and the symptom sum score were significantly higher in the women who had a uTC followed by a visit than in both the women who had no uTC ( $p<0.0001$ for all) and those with a uTC without a following visit ( $\mathrm{p}=0.02$ and $\mathrm{p}<0.01$ for the pain intensities, and symptom sum score). Similar findings were seen in the women who had $\mathrm{uV}$ preceded by a telephone contact versus the women who had no uV ( $<<0.0001$ for all) and those with a uV without a preceding telephone contact $(p<0.01$ for both pain intensities, and $p<0.001$ for symptom sum score). By contrast, no differences were seen between those with no UTC and those with a uTC without a following visit, and between those with no uV and those with a uV without a preceding telephone contact, respectively.

\section{Discussion}

This study showed that interventions with planned nurse-led TFU including oriented structured coaching after benign hysterectomy did not decrease the level of intensity of postoperative pain, the summary score of common postoperative symptoms or the consumption of analgesics, more than in women who had no planned TFU. Women who had a uTC followed by a visit to a health care provider within six weeks of surgery had significantly higher levels of pain intensity and a higher summary score of postoperative 
symptoms, but showed no difference in analgesics consumption, compared to the women who had no UTC or those with a UTC without a following visit. These results were not influenced by the interventions in spite of a significantly lower occurrence of UTCs in women who had planned TFU, in particular when using structured oriented coaching $\mathrm{TFU}^{9}$. Similar results were seen concerning postoperative uVs in health care facilities.

The use of a randomized controlled design, the large number of patients, and the use of repeated measurements constitute major strengths of the study. Moreover, the trial was intended, in an innovative way, to adapt for clinical use an experimental treatment concept based on evidence-based methods. The lack of an a priori power calculation to estimate sample size for the objectives of this study might be seen as a drawback. However, the differences in outcomes between the intervention groups were small and lacked clinical significance. This might support our interpretation of the results.

The content of the TFU may be seen as a limitation because it has not been validated. However, the content of the standard TFU equals what is used by the nurses in daily clinical practice, whereas the structured oriented coaching TFU is experimental. The structured oriented coaching TFU, which was based on elements derived from CBT, was developed by a clinically and scientifically experienced CBT therapist (GS). We therefore believe that both methods had a firm clinical and theoretical foundation and the structured oriented coaching TFU theoretically should be effective in improving recovery.

The single blinding design may be seen as a strength but also a limitation. There is also a risk that the RNs may have mixed up the content of the structured oriented coaching TFU with the standard follow-up strategy components. To prevent this, GS had several education sessions with the RNs where the importance of avoiding a mix of the strategies was emphasized.

Previous research on TFU has evaluated a variety of outcomes for TFU, including enhancing patient safety, improving the quality and continuity of care, reducing adverse events, clarifying patient understanding of discharge care instructions, seeking patient feedback about their experience of care and addressing any concerns about their experience or their recovery [14]. Three systematic reviews have been published concerning TFU after surgery and discharge from hospital [15-17]. The systematic reviews drew similar conclusions that the methodological quality of the included studies was low, they lacked valid and reliable tools to assess patient outcomes, and there was limited evidence of the benefits of the TFU.

To the best of our knowledge, no previous study has evaluated the effect of TFU on postoperative recovery from symptoms and analgesic consumption after hysterectomy. However, we did not observe any benefit of the TFU on recovery from postoperative pain, and the summary score of symptoms or analgesics consumption at any time nor did we find any subgroup that would benefit. Although these results indicate that TFU has no effect on the recovery outcomes we cannot exclude an effect since this study was conducted in an ERAS setting. The women had already received thorough information about the perioperative care and postoperative symptoms and how to treat these before discharge. Thus, the 
standard TFU in this study would probably only confirm what the patient already knew and therefore would not add much to the recovery. On the contrary, the structured oriented coaching TFU was anticipated to have additional effects on the recovery since the coaching was intended to provide the patient with tools to handle the perceived troublesome discomfort better. Since all women received the same perioperative information according to the ERAS program and no differences were seen on any of the outcome measures between the controls and the three TFU groups, it is most likely that TFU and coaching as used in this study do not have an effect on postoperative symptoms and consumption of analgesics. Consequently, the external validity of the trial findings is restricted to settings using similar ERAS programs.

UTC or UV often reflects an unexpected deviation in the recovery for the patient [17]. Women with a UTC followed by a visit to a health care provider reported higher pain intensity and a higher summary score of postoperative symptoms. Similar findings were seen between those with and without a following visit, whereas no differences were found between women with no UTC and those with a uTC without a following visit. The findings were independent of intervention, indicating that the interventions seemed to generate equal effects in these groups.

In spite of the TFU and the use of ERAS, the occurrence of uTCs and uVs was still rather high. This may indicate that having planned contacts even with weekly intervals does not reduce uTCs. We were not able to clearly establish the reasons for this phenomenon, but rapid onset of unforeseen symptoms between two TFU occasions may be a plausible explanation and obviously not preventable by TFU. This might indicate a shortage in the ERAS programs to counteract or prevent such unforeseen events. Although we do not know the specific reasons for the UTCs or the UVs, the results might indicate that pain and other symptoms are probably among the most common reasons for the contacts. Thus, our findings may indicate that the nurses giving telephone counselling in clinical practice were excellent and capable of discriminating alarming clinical symptoms from minor important symptoms that did not need a visit for clinical evaluation.

Patient satisfaction is gaining importance as a measure of quality of care but there is no consistent association between patient satisfaction and clinical outcomes after surgery [18]. Although TFU may increase patient satisfaction with post-discharge care [15], it seems debatable from a health-economic perspective to justify the consumption of resources for TFU without demonstrating clear benefits in clinical outcomes. We did not find such benefits in this study and previously we have shown that TFU did not improve the health-related quality of life [9].

Postoperative recovery is multifactorial and efforts to improve the recovery would probably benefit from being individualized, taking into account the patient's psycho-social status. Prehabilitation, defined as the practice of enhancing a patient's functional capacity before surgery, with the aim of improving postoperative outcomes [19], in association with TFU needs to be evaluated.

\section{Conclusion}


The TFU strategy including the structured coaching program adhered to in this study did not seem to affect recovery from symptoms or consumption of analgesics after benign hysterectomy in an ERAS setting. UTCs and uVs were probably caused by increased pain or other symptoms but were not influenced or preventable by the TFU.

\section{Abbreviations}

ANOVA: analysis of variance

CBT: cognitive behavior therapy

ERAS: Enhanced Recovery After Surgery

POSTHYSTREC: Post-Hysterectomy Recovery

$\mathrm{RN}$ : research nurse

SPSQ: Swedish Postoperative Symptoms Questionnaire

TFU: Telephone Follow-Up

uTC: unplanned telephone contact

uV: unplanned visit

\section{Declarations}

\section{Acknowledgments:}

We are indebted to and appreciate all participating women who unselfish spent time and participated in the trial. All doctors and research nurses in the POSTHYSTREC study group are thanked for their invaluable dedicated work. Statistician, associate professor Mats Fredriksson is appreciated for statistical advice.

The POSTHYSTREC Study Group consisted of members from five hospitals in the Southeast health region of Sweden.

Linköping University Hospital: Preben Kjølhede, MD, PhD, Gunilla Sydsjö, PhD, Ninnie Borendal Wodlin, MD, PhD, Lena Nilsson, MD, PhD, Gulnara Kassymova, MD, Peter Lukas, MD, Petra Langström, RN, Pernilla Nilsson, RN, Linda Shosholli, RN, Sofia Bergström, RN, and Åsa Rydmark Kersley, RN, MSc.

Vrinnevi Hospital, Norrköping: Leif Hidmark, MD, Anders Bolling, MD, Kristina Ekman, RNW, and Karin Granberg-Karlsson, RNW

Ryhov Hospital, Jönköping: Laila Falknäs, MD, Maria Häggström, MD, Ewa Hermansson RNW 
Eksjö Highland Hospital: Tomaz Stypa, MD, Linda Myllimäki, MD, Iréne Johannesson, RNW, and Martina Ekeroth Wikander, RNW.

Värnamo Hospital: Christina Gunnervik, MD, Fatima Johansson, MD Magnus Trofast, MD, Mari-Ann Andersson, RNW, and Carita Jacobsson, RN

\section{Funding}

The study was supported by grants from the Medical Research Council of Southeast Sweden (FORSS155141; FORSS-222211; FORSS-308441, and FORSS-387761), ALF Grants Region Östergötland (RÖ-276871, RÖ-356651, RÖ-448391RÖ 607891, and RÖ-794531), and Futurum - the Academy of Health and Care, Region Jönköping Council (FUTURUM-487481, and FUTURUM 579171). The awarded grants were assessed by external peer reviewers for scientific quality. Linköping University contributed with unrestricted grants. The grant providers were otherwise not involved in the research or the writing of the manuscript.

\section{Competing Interests}

The authors have no relevant financial or non-financial interests to disclose.

\section{Author contribution}

The study was conceptualized by Preben Kjølhede, Gunilla Sydsjö, Lena Nilsson and Ninnie Borendal Wodlin who also wrote the research protocol. The study was conducted by Preben Kjølhede, Lena Nilsson, Gulnara Kassymova and Ninnie Borendal Wodlin. The main author is Gulnara Kassymova. Analyses of data were performed by Preben Kjølhede and Gulnara Kassymova. All authors contributed to revision of the manuscript and all approved the final version of the manuscript.

\section{Ethical approval}

The Regional Ethics Board of Linköping University approved the study (Dnr.2011/106-31, approval date 15/06/2011). This study was performed in line with the principles of the Declaration of Helsinki.

\section{Consent to participate}

Written informed consent was obtained from all women included in the study.

\section{References}

1. Wodlin NB, Nilsson L, Årestedt K, Kjølhede P. Mode of anesthesia and postoperative symptoms following abdominal hysterectomy in a fast-track setting. Acta Obstet Gynecol Scand. 2011;90(4):369-79. https://doi.org/10.1111/j.1600-0412.2010.01059.x 
2. Alkaissi A, Gunnarsson H, Johnsson V, Evertsson K, Ofenbartl L, Kalman S. Disturbing post-operative symptoms are not reduced by prophylactic antiemetic treatment in patients at high risk of post-operative nausea and vomiting. Acta Anaesthesiol Scand. 2004;48(6):761-71. https://doi.org/10.1111/j.00015172.2004.00403.x

3. Fiore Jr JF, Figueiredo S, Balvardi S, et al. How do we value postoperative recovery?: A systematic review of the measurement properties of patient-reported outcomes after abdominal surgery. Ann Surg. 2018;267(4):656-69. https://doi.org/10.1097/SLA.0000000000002415

4. Lee L, Tran T, Mayo NE, Carli F, Feldman LS. What does it really mean to "recover" from an operation? Surgery. 2014;155(2):211-6. https://doi.org/10.1016/j.surg.2013.10.002

5. Berg K, Årestedt K, Kjellgren K. Postoperative recovery from the perspective of day surgery patients: a phenomenographic study. Int J Nurs Stud. 2013;50(12):1630-8.

https://doi.org/10.1016/j.ijnurstu.2013.05.002

6. Mottram A. 'They are marvellous with you whilst you are in but the aftercare is rubbish': a grounded theory study of patients' and their carers' experiences after discharge following day surgery. J Clin Nurs. 2011;20(21-22):3143-51. https://doi.org/10.1111/j.1365-2702.2011.03763.x

7. Renholm M, Suominen T, Turtiainen AM, Leino-Kilpi $\mathrm{H}$. Continuity of care in ambulatory surgery critical pathways: the patients' perceptions. Medsurg Nurs. 2009;18(3):169-73.

8. Sibbern T, Bull Sellevold V, Steindal SA, Dale C, Watt-Watson J, Dihle A. Patients' experiences of enhanced recovery after surgery: a systematic review of qualitative studies. J Clin Nurs. 2017;26(910):1172-88. https://doi.org/10.1111/jocn.13456

9. Kassymova G, Sydsjö G, Borendal Wodlin N, Nilsson L, Kjølhede P. The effect of follow-up contact on recovery after benign hysterectomy: A randomized, single-blinded, four-arm, controlled multicenter trial. J Womens Health (Larchmt). 2020;30(6):872-81. https://doi.org/10.1089/jwh.2020.8752

10. Nelson G, Altman AD, Nick A, et al. Guidelines for pre- and intra-operative care in gynecologic/oncology surgery: Enhanced Recovery After Surgery (ERAS ${ }^{\circledR}$ ) Society recommendations-Part I. Gynecol Oncol. 2016;140(2):313-22. https://doi.org/10.1016/j.ygyno.2015.11.015

11. Nelson G, Altman AD, Nick A, et al. Guidelines for postoperative care in gynecologic/oncology surgery: Enhanced Recovery After Surgery (ERAS ${ }^{8}$ ) Society recommendations--Part II. Gynecol Oncol. 2016;140(2):323-32. https://doi.org/10.1016/j.ygyno.2015.12.019

12. Simple Interactive Statistical Analysis. Allocation [cited 2020 June 24]. Available from: https://www.quantitativeskills.com/sisa/.

13. World Health Organization. Defined Daily Doses (DDD). [Available from: https://www.who.int/medicines/regulation/medicines-safety/toolkit_ddd/en/. 
14. Schuller KA, Lin SH, Gamm LD, Edwardson N. Discharge phone calls: a technique to improve patient care during the transition from hospital to home. J Healthc Qual. 2015;37(3):163-72.

https://doi.org/10.1111/jhq.12051

15. Woods CE, Jones R, O'Shea E, Grist E, Wiggers J, Usher K. Nurse-led postdischarge telephone followup calls: A mixed study systematic review. J Clin Nurs. 2019;28(19-20):3386-99.

https://doi.org/10.1111/jocn.14951

16. Mistiaen P, Poot E. Telephone follow-up, initiated by a hospital-based health professional, for postdischarge problems in patients discharged from hospital to home. Cochrane Database Syst Rev. 2006(4):CD004510. https://doi.org/10.1002/14651858.CD004510.pub3

17. Bahr SJ, Solverson S, Schlidt A, Hack D, Smith JL, Ryan P. Integrated literature review of postdischarge telephone calls. West J Nurs Res. 2014;36(1):84-104. https://doi.org/10.1177/0193945913491016

18. Tevis SE, Kennedy GD, Kent KC. Is there a relationship between patient satisfaction and favorable surgical outcomes? Adv Surg. 2015;49:221-33. https://doi.org/10.1016/j.yasu.2015.03.006

19. Banugo P, Amoako D. Prehabilitation. BJA Education. 2017;17(12):401-5.

https://doi.org/10.1093/bjaed/mkx032

\section{Figures}




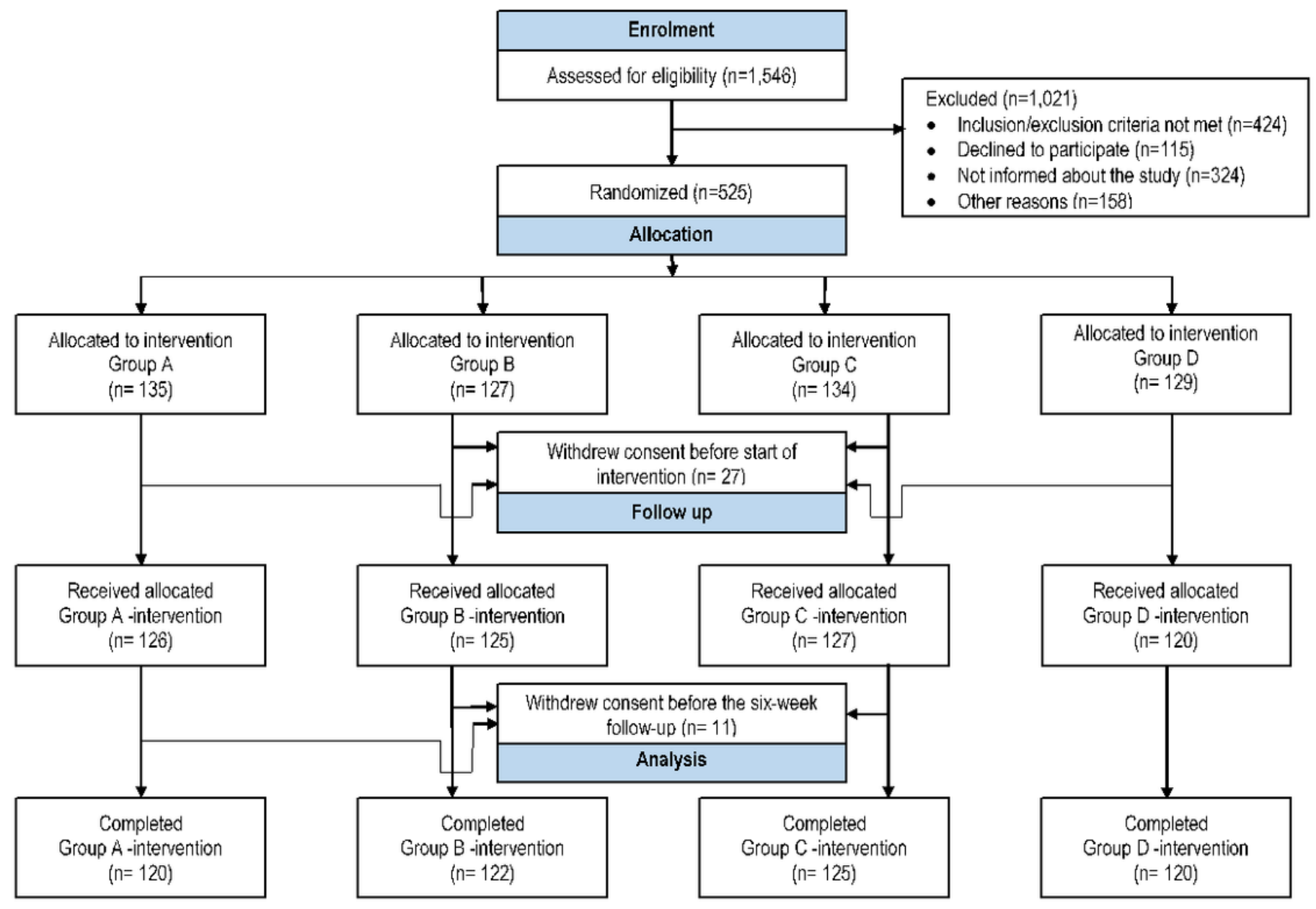

Figure 1

CONSORT flow-chart of participants in the POSTHYSTREC trial. 

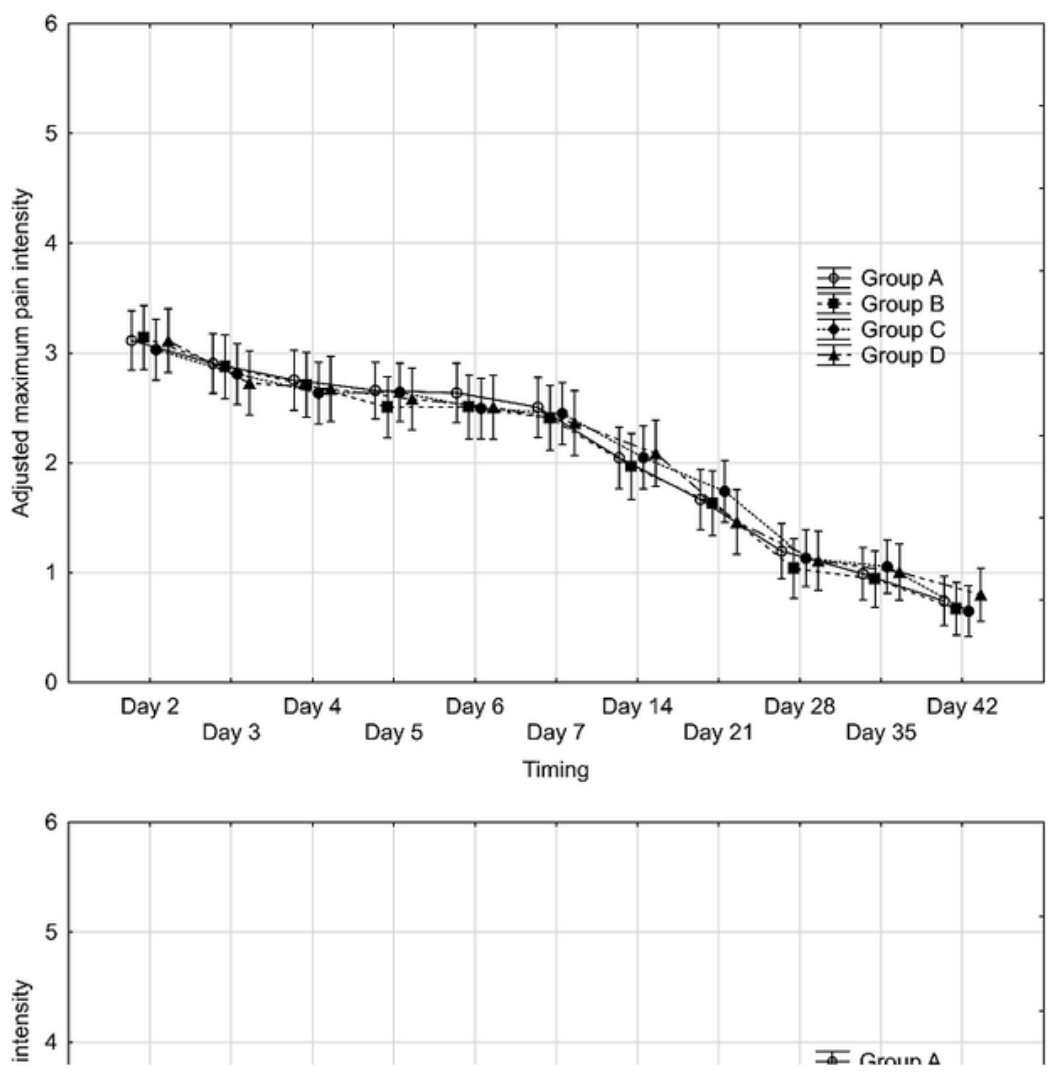

\section{Figure 2}

Maximum pain intensity and average pain intensity after benign hysterectomy from day 2 to day 42 postoperatively in relation to intervention group. Pain intensity measured on a scale from 0 (no pain) to 6 (very severe pain). Results of repeated measures ANOVA are shown in the table below the diagrams. 


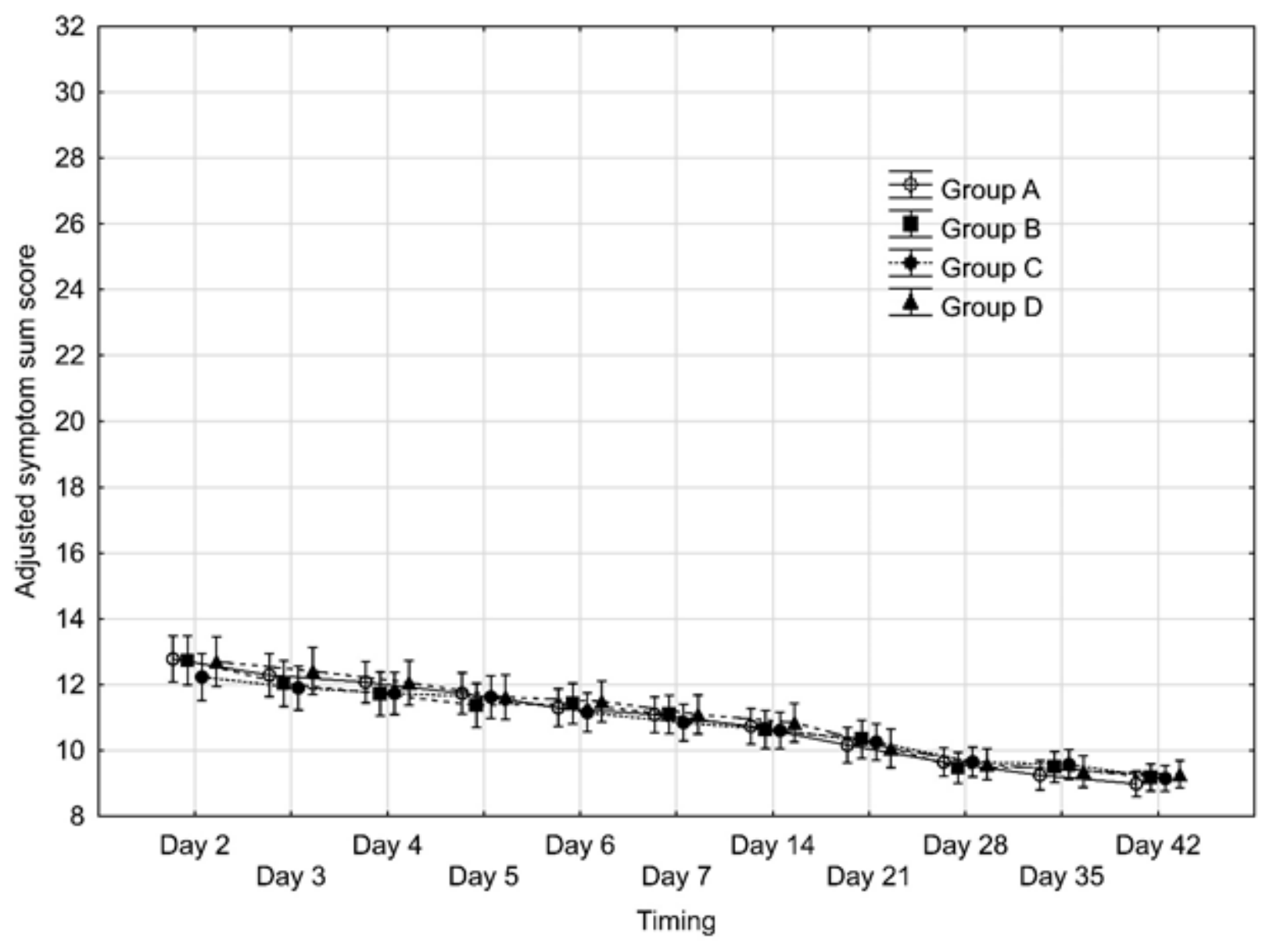

\begin{tabular}{llccc}
\hline & & \multicolumn{2}{c}{ Repeated measures analysis of variance } \\
& & $\begin{array}{c}\text { Between intervention groups } \\
\text { Main effect }\end{array}$ & $\begin{array}{c}\text { Within groups } \\
\text { Effect over time }\end{array}$ & $\begin{array}{c}\text { Interaction effect } \\
\text { Outcome measure }\end{array}$ \\
\hline Symptom sum score & Crude & $p$ & $p$ & $p$ \\
& Adjusted\# & 0.95 & $<0.0001$ & 0.21 \\
& 0.92 & $<0.0001$ & 0.31 \\
\hline
\end{tabular}

\# Adjusted for mental disorder, mode of surgery, consumption of opioids day 2-7, non-opioids day $2-15$, and day of discharge.

\section{Figure 3}

Symptom sum score from day 2 to day 42 postoperatively after benign hysterectomy in relation to intervention group. Symptom sum score ranges from 8 to 32. The higher the sum score the more symptoms. Results of repeated measures ANOVA are shown in the table below the diagram. 

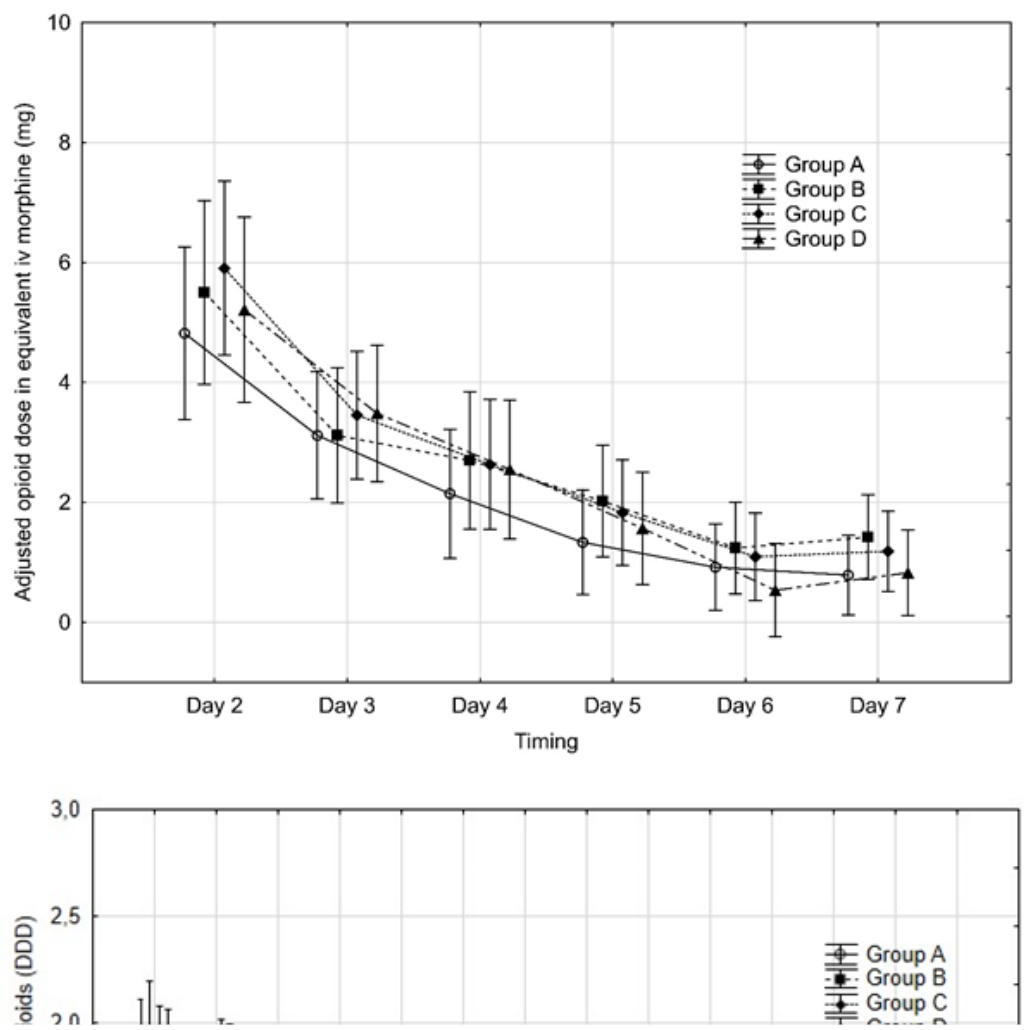

\section{Figure 4}

Consumption of opioids (in equivalent intravenous morphine $(\mathrm{mg})$ ) and non-opioids (in defined daily dose (DDD) according to $\mathrm{WHO}[13]$ ) after benign hysterectomy in relation to intervention group. Results of repeated measures ANOVA are shown in the table below the diagrams. 
A. Unplanned telephone contact
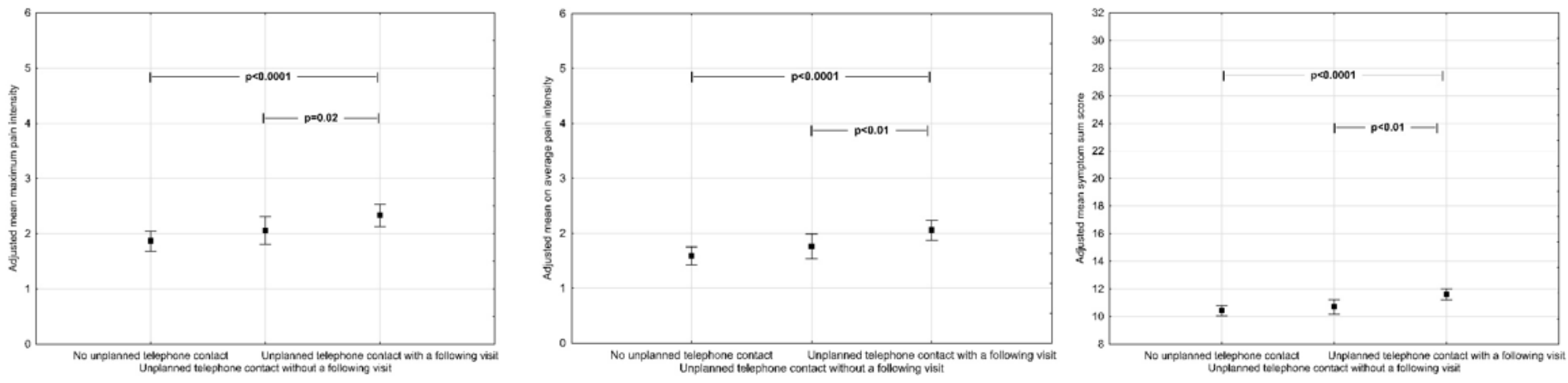

\section{B. Unplanned visit}
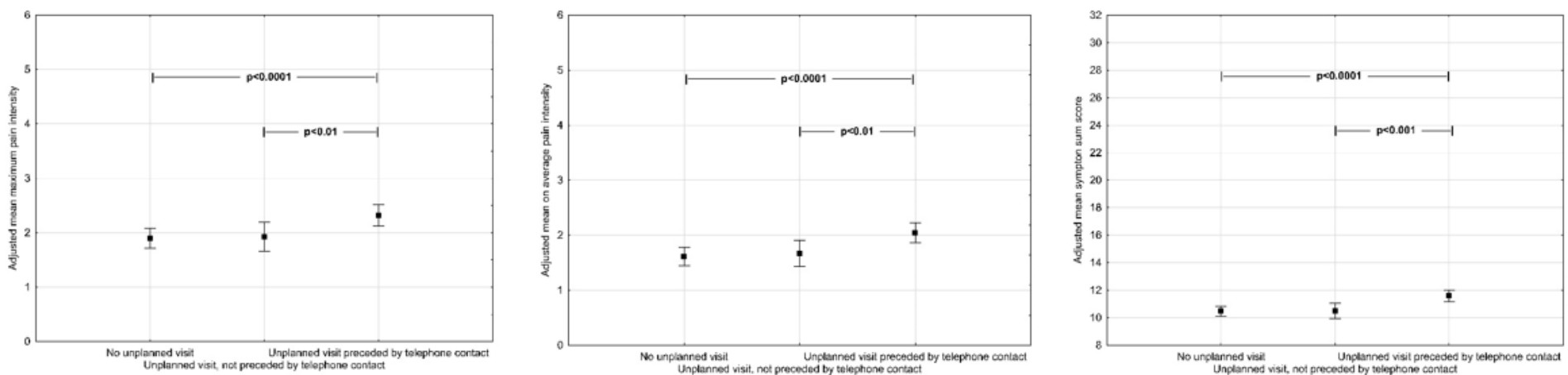

Figure 5

Post-hoc tests of the significant outcomes depicted in Table 3 between groups, A) with and without unplanned telephone contacts, and B) with and without unplanned visits. Plots indicate means and bars represent 95\% confidence interval. 